\title{
TIME PERCEPTION DEFICITS IN ATTENTION-DEFICIT/HYPERACTIVITY DISORDER AND COMORBID READING DIFFICULTIES IN CHILD AND ADOLESCENT SAMPLES
}

\author{
Toplak, M. E., Rucklidge, J. J., Hetherington, R., John, S. C. F, \& Tannock, R.
}

Drs. Toplak, Hetherington, \& Tannock are with the Brain and Behaviour Research Programme, Research Institute of The Hospital for Sick Children. Dr. Rucklidge is currently a Lecturer in Psychology at the University of Canterbury, Christchurch, New Zealand. Mrs. John is currently a doctoral student at the Ontario Institute for Studies in Education of The University of Toronto and with the Brain and Behaviour Research Programme.

This research was supported in part by research grants from the National Institute of Health (RO1HD31714) and Medical Research Council of Canada (MT 13131), an MRC Scientist Award to R.Tannock, a Medical Research Council of Canada Fellowship granted to J. J. Rucklidge, a Canadian Institutes of Health Research (CIHR) Fellowship granted to M. Toplak, and a CIHR Doctoral Scholarship to S. John.

Reprint requests to Dr. Rosemary Tannock, Brain \& Behaviour Research Programme, The Hospital for Sick Children, 555 University Avenue, Toronto, Ontario, Canada M5G 1X8. Email:

Rosemary.Tannock@sickkids.on.ca 


\begin{abstract}
Objective: To investigate time perception in Attention-Deficit/Hyperactivity Disorder (ADHD) with and without comorbid reading difficulties (RD) in child and adolescent participants. Method: In study 1, 50 children with ADHD (31 ADHD, 19 ADHD+RD) and age-matched healthy controls ( $n=50)$, completed three psychophysical tasks: duration discrimination (target duration of $400 \mathrm{~ms}$ versus a foil duration), frequency discrimination (a control condition to evaluate general perceptual ability), and a duration estimation task using the method of reproduction for intervals of $400 \mathrm{~ms}$, 2000 ms, and 6000 ms. Study 2 used the same tasks with an adolescent sample (35 ADHD, 24 ADHD+RD, 39 controls). Results: In both studies, children and adolescents with ADHD and ADHD+RD displayed some impairments in duration discrimination and the precision with which they reproduced the intervals on the estimation task, particularly the shorter $400 \mathrm{~ms}$ interval. The most severe impairments tended to occur in the comorbid ADHD+RD group. No impairments were found on the frequency discrimination task. ADHD participants also displayed significant intraindividual variability in their performance on the estimation task. Finally, working memory, estimated full-scale IQ, and teacher report of hyperactivity/impulsivity were found to differentially predict performance on the time perception measures in the adolescent clinical sample.
\end{abstract}

Conclusions: Deficits in duration discrimination, duration estimation, and intra-individual performance variability may have cascaded effects on the temporal organization of behaviour in children and adolescents with ADHD and ADHD+RD [226 words]

Key Words: time perception, working memory, attention-deficit/hyperactivity disorder, reading difficulties, teacher report, behaviour ratings 


\section{TIME PERCEPTION DEFICITS IN ATTENTION-DEFICIT/HYPERACTIVITY DISORDER AND COMORBID READING DIFFICULTIES IN CHILD AND ADOLESCENT SAMPLES}

Time perception is an adaptive function that facilitates the ability to predict, anticipate, and respond efficiently to coming events. For example, the preparation of fast responses benefit from the ability to predict precisely the point in time when an impending event requires a response. Also, precise representation of temporal information is required for the ability to organize and plan sequences of actions, particularly when sequences of novel or unskilled movements are required (Gibbon et al.,1997; Hazeltine et al., 1998; Ivry, 1997). Time perception is a complex cognitive ability and comprises multiple component processes that engage multiple brain regions, including the neocerebellum, basal ganglia and prefrontal cortex (e.g., Casini \& Ivry, 1999; Mostofsky et al., 2000; Gibbon et al., 1997; Harrington et al.,1998a, 1998b; Ivry \& Keele, 1989; Ivry \& Hazeltine, 1995; Jueptner et al., 1995; Mangels et al.,1998; Meck., 1996; Nichelli et al., 1996a, 1996b; Rubia et al., 1999a, 1999b). Recent work suggests that the neocerebellar cortex and prefrontal cortex (particularly, the dorsolateral prefrontal cortex) participate in a working memory system, which is involved in discrimination of intervals ranging from a few milliseconds to several seconds. Moreover, the neocerebellum may subserve a central timing mechanism, whereas the prefrontal cortex subserves supplementary functions implicated in the acquisition, maintenance and organization of temporal representation in working memory (Casini \& Ivry, 1999; Mangels et al., 1998).

Time perception is postulated to be impaired in Attention Deficit Hyperactivity Disorder, according to current models of ADHD and impulsivity (e.g., Barkley, 1997a, 1997b, 1997c; Barkley et al., 1997; Barkley et al., 2001;Barratt \& Patton, 1983; Gerbing, Ahadi, \& Patton, 1987; Stanford 
\& Barratt, 1996). For example, one recent theoretical model of ADHD proposes that four executive neuropsychological functions are compromised by an underlying impairment in behavioral inhibition, which is believed to be the fundamental deficit in ADHD (Barkley, 1997a). One of these executive functions is working memory, which supports some components of time perception. Impaired time perception in ADHD is also predicted independently by models of impulsivity, which propose a link between time perception and impulsive behavior - the latter being a core feature of ADHD (e.g., Barratt \& Patton, 1983; Gerbing et al., 1987; Stanford \& Barratt, 1996).

Clinical phenomenology and empirical evidence is consistent with the hypothesized time perception deficits in ADHD. For example, clinical descriptions indicate that individuals with ADHD have marked difficulties in conforming to directions containing time parameters, meeting deadlines for work assignments, and in adjusting the timing of their behavior to the pacing of the immediate context (e.g., calling out in class, interrupting an ongoing conversation, difficulty waiting turn). Also, a diverse array of findings from studies of cognitive processes involved in motor response control supports the hypothesis of impaired time perception in ADHD. Findings include: 1) deficits in working memory that are believed to play a major role in time perception; 2) adverse effects on task performance of either very brief or long delays between stimuli, and of temporal uncertainty; 3) production of slow and variable responses on tasks with a "fast” instruction set; 4) a high rate of premature responses in experimenter-paced tasks; and 5) impairments in timing motor output (e.g., Barkley et al., 1996; Karatekin \& Asarnow, 1998; Mariani \& Barkley, 1997; Rubia et al., 1999a, 1999b; Sergeant \& Scholten, 1985; Sonuga-Barke et al., 1998; Zahn et al., 1991). Some recent findings from neuroimaging studies of ADHD have also reported structural anomalies in the cerebellum, basal ganglia, and prefrontal cortex (e.g., Berquin et al., 1998; Castellanos, 2001;

Castellanos et al., 1996, 2001; Mostofsky et al., 1998). 
Direct evidence of time perception deficits in ADHD is not only extremely limited, but also findings are inconsistent (Barkley et al., 1997b; Capella et al., 1977). Moreover, the few available studies differed in sampling procedures (school vs. clinic sample), diagnostic criteria (clinical diagnosis of ADHD vs. ratings of hyperactivity or inattention), methods of assessing time perception (duration discrimination vs. time production or time reproduction), and inconsistency in the range of intervals used (often in the range of $7 \mathrm{sec}$ to $60 \mathrm{sec}$ ). This makes it difficult to integrate findings across the different studies. Furthermore, none of the existing studies considered the possible impact of comorbidity. In particular, the failure to control for comorbid reading difficulties (RD) is potentially problematic given the evidence of impairment in time-related performance in children with RD (Farmer \& Klein, 1995; Fawcett \& Nicolson, 2001; Nicolson et al., 2001; Wolf, 2001).

The purpose of the two studies presented here was to provide a further test of the hypothesized time perception deficits in ADHD, and to examine the persistence of deficits developmentally via a child (study 1) and an adolescent (study 2) sample. Specifically, both studies evaluated duration discrimination (i.e., perception) and duration estimation (by method of reproduction) in participants with ADHD by using psychophysical tasks that afford more precise measurement than the tasks used in the previous studies. The duration discrimination task required participants to determine which of two intervals was the longest - a target duration of 400 ms versus a comparison duration. A non-temporal task was included as a control condition to evaluate whether the design of the task, generalized perceptual impairment, or difficulty with auditory signals may have influenced performance on the duration discrimination task. This task was called the frequency discrimination task, and used a target frequency of $3000 \mathrm{~Hz}$ versus a comparison frequency. Duration estimation was evaluated using the method of reproduction, a reliable method that does not require verbal responses or knowledge of culturally determined temporal units (Zakay, 1990). A wider range of duration was used than in previous studies, since there is evidence that timing of very 
short intervals (milliseconds) and longer intervals (seconds) may be distinguished behaviorally and neurally. That is, timing in the range of milliseconds can be achieved relatively automatically by direct readout from an internal timing mechanism with little or no demand on working memory or strategy use. Neurally, timing in this range - a range associated with motor control - has been linked with the cerebellum (Ivry, 1996; Mangels et al., 1998). By contrast, timing in the range of several seconds involves working memory (to hold and manipulate information on-line) and strategy use (e.g., counting), and may be subserved by a neural network involving basal ganglia and prefrontal cortex (Meck 1996; Ivry 1996, Mangels et al., 1998; Gibbon et al., 1997). Also, in both studies 1 and 2, the ADHD sample was stratified for comorbid reading difficulties to determine the impact of this comorbidity on time perception performance.

Importantly, the use of these three measures provides an important range of time perception measures that have never before been examined in a sample of children and adolescents, or in a sample of participants with ADHD and RD. The frequency discrimination task, directly analogous to the duration discrimination task, provides an important control for general auditory perception. In the duration discrimination task, the participant's task is to discriminate the longer from the shorter duration. The dependent measure in this task has no speeded responding or motor timing component, therefore providing a purely cognitive index of duration discrimination ability. The duration estimation task is a somewhat different paradigm of time perception than the duration discrimination task (Block, 1990), as participants must reproduce an interval of time. In addition, this task has a motor component that may factor into the dependent measures of this task. If in fact ADHD is characterized by time perception deficits, it is expected that both children and adolescents with ADHD will display impaired performance on the duration discrimination and estimation tasks, but not on the frequency discrimination control task. If individuals with reading difficulties also have deficits in time perception, the ADHD+RD child and adolescent groups may display significantly 
more impaired performance than ADHD and control participants. Regression analyses were also performed with the clinical groups to examine predictors of time perception performance, specifically to examine whether there are associations between time perception and working memory measures (Ivry, 1996).

\section{STUDY 1}

\section{Participants}

Two groups of children participated: 50 children (22\% female) with a confirmed clinical diagnosis of ADHD and 50 comparison children ( $40 \%$ female). Approximately $40 \%(\mathrm{n}=19)$ of the children with ADHD had comorbid reading difficulties, according to the criteria described below. All children were between the ages of 6.4 years and 11.9 years (mean $=9.2$ years). The children with ADHD were recruited from an outpatient department of psychiatry in a pediatric academic health sciences center for assessment of attention, behavior, and learning problems. Data from children with ADHD were compared with those from an age-matched subset of healthy children, who had been recruited from visitors to the Ontario Science Centre to participate in a developmental study of time perception.

ADHD Sample. All children had a diagnosis of ADHD confirmed by a multidisciplinary clinical diagnostic assessment. The assessment comprised two semi-structured clinical diagnostic interviews (face-to face interview with parents; telephone interview with teachers), standardized behavior rating scales completed by the parents and teacher, and a comprehensive child assessment. The parent interview [Parent Interview for Child Symptoms-IV (PICS-IV); Schachar \& Ickowicz, 1994; unpublished manuscript] covers the child's development and current behavior and uses the DSM-IV criteria for externalizing and internalizing disorders of childhood. The PICS-IV is modeled on the Schedule for Affective Disorders and Schizophrenia for School-Age children-Present and Lifetime Version (K-SADS-PL; Kaufman et al., 1997), but does not use skip-out criteria for the 
externalizing disorders and only probes for descriptions of behavior in the home and community settings (i.e., not school setting). The PICS-IV was the diagnostic interview of choice in the hospital clinic at this time. The teacher interview [Teacher Telephone Interview-IV (TTI); Tannock et al., 1999] follows the same basic format as the PICS, but restricts probes to descriptions of behavior in the school setting, covers symptoms of ADHD, ODD, and CD in detail, and screens for internalizing disorders. Reliability and validity for the DSM-III-R versions of both interviews are high, with kappa of .84 for diagnosis (Schachar, Tannock, Marriott \& Logan, 1995). The PICS-IV and TTI-IV were administered independently by trained clinicians that rated the behavior on a 4-point scale of severity and frequency based on the elicited descriptions of behavior. To be classified as ADHD, children had to meet DSM-IV criteria for ADHD, defined as at least six of nine inattentive or hyperactive-impulsive symptoms, or both. To ensure pervasive impairment, children were required to meet criteria for ADHD in the parent or teacher interview, but also exhibit a minimum of four inattentive or four hyperactive-impulsive symptoms according to the other informant.

The child assessment included the Wechsler Intelligence Scale for Children - Third Edition (WISC-III; Wechsler, 1991), the arithmetic and reading subtests of the Wide-Range Achievement Test-3 (WRAT-3; Wilkinson, 1993), and the Word Attack and Word Identification subtests of the Woodcock Reading Mastery Test-Revised (Woodcock, 1987). Children with a full-scale intelligence quotient (IQ) score of less than 80, any evidence of neurological dysfunction, poor physical health, uncorrected sensory impairments, or a history or current presentation of psychosis were excluded from the study. Sample characteristics and scores on these tests are displayed in Table 1.

[Insert Table 1]

Classification of Reading Difficulties. For the present study, a definition of low achievement in single-word reading was used to classify reading difficulties, since there is little or no evidence to support the validity of an IQ-discrepancy model (Fletcher et al., 1998; Francis et al., 1996; 
Stanovich \& Siegel, 1994). Specifically, children with a composite standardized reading score of

less than 90 (i.e., less than $25^{\text {th }}$ percentile) were classified as having comorbid reading difficulties. The composite reading score was calculated from the average of the standardized scores on three measures of reading; the Reading subtest of WRAT-3 (Wilkinson, 1993) and the Word Identification and Word Attack subtests of the WRMT-R (Woodcock, 1987). The precise cut-point score is arbitrary but a standardized reading score of 90 is used widely in the USA to represent the definition of reading disability (Fletcher et al., 1998; Frankenberger \& Fronzaglio, 1991).

Comparison Sample. Parents had confirmed on a questionnaire that their child was in good physical health, had no known problems with attention, behavior or learning, nor any neurological dysfunction, sensory impairment, major medical or mental health problems, and were not on any medication for any clinical condition. Standardized measures of intellectual function and academic achievement were not available for this comparison group of children, which is one limitation of this first study. The mean age of children in this comparison group was 9.3 years (SD 1.3 years). Information on parental education and ethnicity was not collected, but most parents would be likely to have a strong educational background (e.g., completed at least some post-secondary education), based on our previous studies conducted at this science centre (e.g., Williams et al., 1999).

\section{Time Perception Tasks}

Each child completed two implicit timing tasks including a duration discrimination task (with frequency discrimination as a control task) and a duration estimation task. All children were tested individually. Children with ADHD were tested in a quiet testing room in the pediatric academic health sciences center, whereas the healthy comparison group was tested in a quiet testing room at the science center using the same apparatus, tasks, and testing procedures as used with the children with ADHD. 
The tasks, which were developed by Hetherington et al. (2000) were programmed in Turbo Pascal for an IBM-compatible Pentium series computer that presented the stimuli and collected the data. The internal tone generator of the computer was used to generate the auditory signals. Each computer was equipped with adjustable padded headphones through which the auditory signals could be presented without the hindrance of background noise. Participants responded to the stimuli by pressing the appropriate response button on a 3-button response box: the two outer buttons were used for the duration and frequency threshold tasks and the center button was used for the duration estimation task.

Duration and Frequency Discrimination Tasks. Both tasks were presented in similar 2alternative forced choice trials. In the duration discrimination task, participants were presented with two unfilled intervals (target, comparison), each defined by brief tones (50 ms, $1000 \mathrm{~Hz}$ ) at the beginning and end of the interval. Unfilled intervals were used to minimize any confound from ongoing processing of the auditory stimuli (Ivry, 1996), however, the psychological significance of filled versus unfilled intervals in timing measures is a contentious issue in the time perception literature (Block, 1990). The target interval of 400 ms was randomly presented as either the first or second duration. The comparison interval was always longer than $400 \mathrm{~ms}$ and was adjusted up or down in $10 \mathrm{~ms}$ increments depending upon the accuracy of the participant's responses. The target and comparison interval were separated by $800 \mathrm{~ms}$ and the inter-trial interval was $1000 \mathrm{~ms}$. Participants were instructed to press the left button if they thought the first interval tone was longer, and the right hand button if they thought the second one was longer. On-screen cues in the form of numbered boxes mapping the tones in each trial to the left-right response buttons were always available to provide a guide for participants' responses. Response buttons and on-screen cues were color coded for further clarity, and the on-screen cues would flash to register the participants' responses. Thus, working memory demands for on-line maintenance of instructions were minimal. 
No feedback about errors was provided. An up-down-transformed-response (UDTR) adaptive psychophysical procedure was used to track $80 \%$ accuracy (Wetherill \& Levitt, 1965). The procedure stopped after 6 reversals of direction, averaging the last 5 reversal values to produce the estimate of discrimination (i.e., the threshold). The format of the frequency discrimination task was similar, with a target frequency of $3000 \mathrm{~Hz}$. The target and comparison tones were each presented for a duration of $200 \mathrm{~ms}$ and were separated by $500 \mathrm{~ms}$. The inter-trial interval was $800 \mathrm{~ms}$. Parameters were set based on pilot studies and Monte Carlo simulations to minimize the number of trials to convergence and the overall run time, while optimizing performance. Dependent measures were the estimated mean duration threshold and mean frequency threshold that could be discriminated from the target duration and target frequency, respectively, with about $80 \%$ accuracy.

Duration Estimation by Method of Reproduction Task. The duration estimation task used the method of reproduction for intervals of $400 \mathrm{~ms}, 2000 \mathrm{~ms}$, and $6000 \mathrm{~ms}$. The intervals were chosen to vary in demand on working memory (i.e., the $400 \mathrm{~ms}$ interval placed little or no demand, whereas the 6000 msec interval had the greatest demands). Each interval was signaled with $1000 \mathrm{~Hz}$ boundary tones of 50 ms duration. The experimental task comprised 4 blocks of 15 trials per block, with 5 trials of each interval presented in a quasi-random order that remained constant across all participants. Each block began with an on-screen countdown from five. The intertrial interval was set at $1500 \mathrm{~ms}$. Each trial began with the initial boundary tone of the interval, followed by the second boundary tone. After $500 \mathrm{~ms}$, subjects were prompted for their response with a question mark presented in the middle of the screen for 200 ms. Participants reproduced the interval by tapping the beginning and end of the interval on the center button of a 3-button response box. At $500 \mathrm{~ms}$ after responding, the subject’s response was acknowledged with “OK” displayed centrally for 200 ms. Dependent measures included the mean (and standard deviation) of the estimated duration for each of the three intervals. While the standard deviation of the mean reflects the within group variability 
(that is, variability between participants), the standard deviation measure of performance reflects intra-individual variability, or variability of performance within a given individual.

\section{Results}

$\underline{\text { Outliers }}$

There were some individuals who displayed extreme performance on individual tasks but were within a normal range on others, specifically on tasks where reaction times were the dependent measure. The data from these univariate outliers were included in the statistical analyses.

Tabachnick and Fidell's (1989) most conservative score changing option was selected for only those tasks on which these participants deviated extremely. Each deviant score was changed to equal the next highest score in the distribution, plus one unit. Thus, the score remained as the most extreme in the distribution while at the same time minimized the skew they created in the sample. This procedure was applied on the following measures: mean performance on the duration discrimination task ( $\mathrm{n}=2 ; 1$ ADHD, 1 ADHD+RD), and scores on the duration estimation task [400 ms duration $(\mathrm{n}=1, \mathrm{ADHD}+\mathrm{RD})]$; and the standard deviation score on the $2000 \mathrm{~ms}$ duration ( $\mathrm{n}=1$; ADHD+RD). Group Differences in Duration and Frequency Discrimination

Group differences were tested using one-way analysis of variance for each dependent measure. Study results are summarized in Table 2. The groups differed in duration discrimination, but not frequency discrimination. Scheffé's posthoc procedure was used in both study 1 and 2 because it is the most conservative and robust in the face of unequal n's in groups and violations of the homogeneity of variance assumption (Kirk, 1982). In the posthoc analyses, both children with $\operatorname{ADHD}(p<.01)$ and ADHD+RD $(p<.05)$ were less able to discriminate among durations in the 400 ms range, compared to the age-matched comparison group. However, the children with ADHD and ADHD+RD did not differ from each other or from the comparison group in their ability to discriminate frequencies in the $3000 \mathrm{~Hz}$ range. 


\section{[Insert Table 2]}

\section{Group Differences in Duration Estimation by Reproduction}

Inspection of the mean scores for duration estimation presented in Table 2 indicate that the pattern of reproduction for each of the intervals was similar across all three groups. That is, the average duration of their reproductions was longer than the target 400ms interval, somewhat shorter than the $2000 \mathrm{~ms}$ interval, and much shorter than the $6000 \mathrm{~ms}$ target interval. Also, all children were highly variable in their estimations and reproduced intervals. An analysis of variance for repeated measures across interval (3 levels: 400 ms, 2000 ms, and 6000 ms) was conducted separately for mean duration and variability (SD) of the reproduced intervals. For mean duration, both the main effects for group and interval were significant, as well as the group $\mathrm{X}$ interval interaction. Simple effects analysis revealed that the ADHD+RD group exhibited significantly longer reproductions of the 400 ms interval than the comparison group $(p<.05)$, but significantly shorter intervals for the 6000ms $(p<.01)$ interval compared to both the ADHD and comparison groups, who did not differ. For the variability (SD) of the duration of the reproduced intervals, the repeated-measures ANOVA revealed significant main effects for group, interval, and a significant group $\mathrm{X}$ interval interaction. Simple effects analysis indicated that both children with ADHD and ADHD+RD were significantly more variable than the comparison group at the $2000 \mathrm{~ms}(p<.05)$ and $6000 \mathrm{~ms}(p<.001)$ interval levels. The ADHD+RD $(p<.01)$ group also displayed significantly more variability at the $400 \mathrm{~ms}$ interval level than the ADHD and comparison groups.

\section{$\underline{\text { Effects of ADHD Subtype, Gender, and Other Comorbid Disorders }}$}

Analyses of variance were conducted to determine the effects of ADHD subtype, gender, and other comorbid disorders (specifically, Oppositional Defiant Disorder, Conduct Disorder, and Separation Anxiety). In the child study, 82\% of the sample met criteria for the combined subtype. In analyses to examine whether ADHD subtype (inattentive or combined collapsed across reading 
difficulties) was related to performance on the time perception measures, no such differences were obtained. On the time perception measures, only one effect of gender was significant on the time estimation task. Specifically, boys displayed significantly more variability at the 2000 ms interval than girls on the estimation task $[F(1,98)=9.60, p<.01]$. No effects of comorbid disorders were observed on the time perception measures.

$\underline{\text { Relationships Between Time Perception, Intellectual, Achievement and Behaviour Rating Measures }}$ Correlational analyses were conducted to determine relationships between performance on the time perception measures, ADHD symptoms (from parent and teacher reports), and intellectual and academic functioning. This analysis included the clinical sample (ADHD, ADHD+RD), as not all of this data was available for the comparison group. Full data was available for 48 of the clinical participants, and overall, few significant relationships were obtained. A significant correlation was obtained between duration threshold and WISC-III full-scale IQ $(r=-.32, p<.05)$ on the duration discrimination task. A significant relationship was obtained between the $400 \mathrm{~ms}$ reproduction on the estimation task and the WISC-III Digit Span Standard score $(r=-.32, p<.05)$. Finally, a significant relationship was also obtained between the intra-individual variability at the $2000 \mathrm{~ms}$ interval on the estimation task and the Digit Span Standard score $(r=-.30, p<.05)$. No other significant relationships were obtained.

In summary, children with ADHD and ADHD+RD exhibited impairments in the ability to discriminate brief intervals of around $400 \mathrm{~ms}$, but not in the ability to discriminate tone frequencies around $3000 \mathrm{~Hz}$. Also, children with ADHD+RD were less precise and reliable in their reproduction of intervals in the range of $400 \mathrm{~ms}$ and $6000 \mathrm{~ms}$, and both children with ADHD and ADHD+RD displayed considerable variability in their performance. Few relationships were obtained between the time perception measures and the intellectual, achievement, and behaviour rating measures, although the relationships obtained did suggest some dissociation of performance between the duration 
discrimination and estimation tasks. The same time perception measures were investigated in a sample of adolescents in study 2.

\section{Participants}

\section{STUDY 2}

Two groups of adolescents participated: 59 adolescents (40.7\% female) with a confirmed clinical diagnosis of ADHD and 39 comparison adolescents (53.8\% female). Approximately 41\% $(n=24)$ of the adolescents with ADHD had comorbid reading difficulties, according to the criteria described below. All adolescents were between the ages of 13 years and 16 years (mean 15.0 years). Thirty-three (55.9\%) of the adolescents with ADHD were recruited from patients who were previously assessed in the Department of Psychiatry with a confirmed diagnosis of ADHD in childhood based on a standard clinical diagnostic protocol: the Parent Interview for Child Symptoms (PICS-IV, Schachar and Ickowicz, unpublished), and standardized parent and teacher behavior rating scales. The remaining clinical participants were recruited through advertisements at pediatric offices as well as from new referrals to the Hospital for Sick Children. Adolescents in the control comparison group were recruited through hospital staff and community resources. All adolescents participating in the study were native English speakers.

ADHD Sample. All adolescents had a diagnosis of ADHD confirmed by a multidisciplinary clinical diagnostic assessment. The assessment comprised a semi-structured clinical diagnostic interview (face-to-face interview with parents and adolescents separately), and two standardized behaviour rating scales completed by parents, teachers, and adolescents. The diagnostic interview [Schedule for Affective Disorders and Schizophrenia for School-Age Children-Present and Lifetime Version (K-SADS-PL)] generates both DSM-IIIR and DSM-IV diagnoses. A PhD level clinical psychologist (JR) conducted all interviews. This semi-structured interview has been used extensively to make diagnostic decisions based on DSM criteria and has been validated with 
children aged 6 to 17 (Kaufman et al., 1997). The PICS-IV was not used in this study, as the PICSIV was designed for school-aged children and has not been validated for use with adolescents. The Conners' Rating Scales-Revised (Conners, 1997) was given to parents and teachers to obtain additional behaviour rating measures. To assess for presence or absence of ADHD, the following diagnostic algorithm was used: 1) the child met DSM-IV criteria for ADHD according to the clinician summary based on the K-SADS parent and adolescent interview, 2) met the clinical cutoffs for the externalizing symptoms of ADHD on the Conners teacher questionnaires in order to ensure pervasiveness of symptoms across settings, and 3) showed evidence of ADHD symptoms prior to the age of seven established either through a past diagnosis of ADHD or in new cases, according to parental report and school report cards. The presence/absence of DSM-IV internalizing disorders was based on a clinician summary based on the information gathered from both the parent and adolescent K-SADS interview. Note that the information from the adolescent K-SADS did not supersede parental report for the presence/absence of externalizing symptoms.

The adolescent assessment included parts of the Wechsler Intelligence Scale for Children Third Edition (WISC-III; Wechsler, 1991), including the Vocabulary, Block Design, Digit Span, Arithmetic, Coding, and Symbol Search subtests. Other assessment included the Arithmetic, Spelling, and Reading subtests of the Wide Range Achievement Test-3 (WRAT-3; Wilkinson, 1993) and the Word Attack and Word Identification subtests of the Woodcock Reading Mastery Test Revised (Woodcock, 1987). Adolescents with an estimated IQ of at least 80 (using the Block Design and Vocabulary subtests of the WISC-III), any evidence of neurological dysfunction, serious medical problems, uncorrected sensory impairments, or a history or current presentation of psychosis were excluded from the study. Notably, the ADHD adolescents were comprised of a high proportion of inattentive subtypes as compared to the child sample in study 1 . Table 3 presents demographic characteristics and participants’ scores on these tests. 


\section{[Insert Table 3]}

Classification of Reading Difficulties. A definition of low achievement in single-word reading or spelling was used to classify reading difficulties. Adolescents were classified as having comorbid reading difficulties if they had a standard score below the $25^{\text {th }}$ percentile (SS 90) on at least one of the following subtests: word identification or word attack subtests of the Woodcock Reading Mastery Test-Revised (WRMT-R; Woodcock and Mather, 1989) or the spelling or reading subtests of the Wide-Range Achievement Test (WRAT-III; Wilkinson, 1993).

Comparison sample. Parents and adolescents confirmed on the K-SADS interview and the Conners' questionnaire that their adolescent did not have any Axis I diagnosis other than a specific phobia, or any history or current complaints of problems in attention, behavior, mood disturbances, or learning. Adolescents in the comparison sample were also excluded if they had scores below the $25^{\text {th }}$ percentile on any of the standardized tests of arithmetic, reading, or an estimated IQ below 80 . $\underline{\text { Time Perception Measures }}$

The time perception tasks from study 1 were utilized: the duration discrimination task, the frequency discrimination control task, and the duration estimation by method of reproduction task (using intervals of $400 \mathrm{~ms}, 2000 \mathrm{~ms}$, and $6000 \mathrm{~ms}$ ).

\section{Results}

\section{$\underline{\text { Outliers }}$}

As in study 1, there were some individuals who displayed extreme performance on individual tasks but were within a normal range on others, specifically on tasks where reaction times were the dependent measure. These outliers were treated in the same manner as in study 1, that is changing each deviant score to equal the next highest score in the distribution, plus one unit. This procedure was applied on the following measures: mean performance on the duration discrimination task $(\mathrm{n}=1$, ADHD) and scores on the duration estimation task [400 ms duration ( $n=1 ;$ ADHD+RD)]. 


\section{Group Differences in Duration and Frequency Discrimination}

Group differences were tested using one-way analysis of variance for each dependent measure, and the descriptive statistics are summarized in Table 4. The groups differed in duration discrimination, but not frequency discrimination. Specifically, the adolescents with ADHD+RD were less able to discriminate among durations in the $400 \mathrm{~ms}$ range, compared to the adolescents with ADHD and age-matched comparisons $(p<.05)$.

\section{[Insert Table 4]}

\section{Group Differences in Duration Estimation by Reproduction}

An analysis of variance for repeated measures across interval was conducted separately for the mean duration and standard deviation scores. For mean duration, the main effect for interval and the group $\mathrm{X}$ interval interaction were significant, but the main effect for group was not significant. Simple effects analysis revealed that the adolescents with ADHD+RD were significantly less precise in their reproduction of the $400 \mathrm{~ms}$ interval compared to the adolescents with ADHD and the comparison group ( $p<.05$ ), but this was not the case for the $2000 \mathrm{~ms}$ and $6000 \mathrm{~ms}$ intervals. For the

intra-individual variability (SD) of the reproduced intervals, the repeated-measures ANOVA revealed significant main effects for group, interval, and a significant group X interval interaction. Simple effects analysis indicated that the ADHD+RD group displayed significantly more variability than the ADHD and comparison group at the $400 \mathrm{~ms}$ interval $(p<.01)$, and adolescents with ADHD and ADHD+RD displayed significantly more variability at the $2000 \mathrm{~ms}(p<.001)$ and $6000 \mathrm{~ms}$ $(p<.001)$ intervals than the comparison group.

\section{Group Differences in Working Memory Measures}

An analysis of variance (ANOVA) was conducted with the Digit Span and Arithmetic Standard Scores in order to test differences between groups in working memory. Significant differences between groups were obtained on both the Digit $\operatorname{Span}(\underline{F}(2,92)=12.47, \underline{p}<.0001)$ and 
Arithmetic $(\underline{\mathrm{F}}(2,91)=14.76, \underline{\mathrm{p}}<.0001)$ Standard Scores. The ADHD+RD $(\underline{\mathrm{M}}=7.17, \underline{\mathrm{SD}}=2.64)$ group had significantly lower Digit Span scores than the control $(\underline{\mathrm{M}}=10.66, \underline{\mathrm{SD}}=2.93)$ and ADHD groups $(\underline{M}=10.44, \underline{S D}=2.85 ; \underline{p}<.001)$. The same pattern was observed for the Arithmetic scores. That is, the ADHD+RD ( $\underline{\mathrm{M}}=6.96, \underline{\mathrm{SD}}=2.95)$ group had significantly lower Digit Span scores than the control $(\underline{\mathrm{M}}=11.43, \underline{\mathrm{SD}}=3.18)$ and ADHD groups $(\underline{\mathrm{M}}=10.06, \underline{\mathrm{SD}}=3.15 ; \underline{\mathrm{p}}<.001)$.

As some have argued that short-term memory and working memory are often used interchangeably when in fact they are separable constructs (Engle, 2002; Engle, Tuholski, Laughlin, \& Conway, 1999), additional group difference testing was done with the Digit Span Forwards and Backwards subtests. Standard scores for the Digits Forward and Backward scores were derived (WISC-III PI, 1999). A repeated measures design was used to examine differences between groups on these two measures, with performance on the Digits Forward and Backwards serving as the within subjects factor. Only group was found to be significant, $(\underline{F}(2,91)=14.78, \underline{p}<.0001)$. The ADHD+RD ( $\underline{\mathrm{M}}=7.43, \underline{\mathrm{SD}}=2.27)$ group performed worse on Digits Forward than the control $(\underline{\mathrm{M}}=10.37, \underline{\mathrm{SD}}=3.28)$ and $\mathrm{ADHD}(\underline{\mathrm{M}}=10.21 ; \underline{\mathrm{S}}=2.95)$ groups $(\underline{\mathrm{p}}<.0001)$, and the ADHD+RD $(\underline{\mathrm{M}}=7.74, \underline{\mathrm{SD}}=2.51)$ group performed significantly worse on Digits Backward than the control $(\underline{\mathrm{M}}=11.02, \underline{\mathrm{SD}}=2.40)$ and $\mathrm{ADHD}(\underline{\mathrm{M}}=10.36, \underline{\mathrm{SD}}=2.52)$ groups $(\underline{\mathrm{p}}<.0001)$. $\underline{\text { Effects of ADHD Subtype, Gender, and Other Comorbid Disorders }}$

With respect to ADHD subtypes, 79\% of participants met criteria for the inattentive subtype in the adolescent sample. When an analysis of variance was conducted with subtype and performance on the time perception measures, no significant differences or trends were observed. Notably, one of the unique characteristics of this adolescent sample is the relatively high representation of female adolescents with ADHD and ADHD+RD. Therefore, gender was also considered as a variable of interest in these analyses, and no gender differences were found on any of the time perception measures. 
The impact of comorbid disorders on the time perception measures was also examined, specifically, the presence of Oppositional Defiant Disorder (ODD), Conduct Disorder (CD), and Generalized Anxiety Disorder (GAD). When ODD and GAD were examined, no statistically significant effects were obtained. One significant difference did emerge with the presence of CD on the estimation task. Specifically, participants with CD reproduced a significantly longer estimation $[F(1,95)=16.27, p<.001]$ and displayed significantly more variability $[F(1,95)=16.03, p<.001]$ on the $400 \mathrm{~ms}$ interval of the estimation task than participants who did not have CD. Importantly, only five participants (four ADHD and one ADHD+RD) met criteria for CD in this sample. Taking into account the effect of $\mathrm{CD}$, the analysis of variance was carried out by excluding these five participants. When this analysis was done, the previously reported group differences were maintained on the duration estimation task.

Relationships Between Time Perception, Intellectual, Achievement, and Behaviour Rating Measures

Correlational analyses were conducted to determine relationships between performance on the time perception measures, ADHD symptoms (from parent and teacher reports), and intellectual and academic functioning. Analyses were conducted separately for clinical (ADHD, ADHD+RD) and comparison groups to examine whether the relationship between these variables co-vary differently in these groups. The Pearson correlation co-efficients are presented in Table 5.

\section{[Insert Table 5]}

The relationships obtained between the time perception and intellectual and behaviour measures differed in the clinical and comparison groups. In fact, performance seemed to be completely dissociated between the clinical and comparison groups. The reasons why performance may be completely dissociated in the clinical and comparison groups are unknown, but we proceeded to interpret correlations separately for the clinical and comparison groups given this pattern of findings. In the comparison group, significant correlations were obtained between the 
intellectual and behaviour measures and the frequency discrimination task. In the clinical group, performance on the duration discrimination task was significantly correlated with all of the working memory measures (including, the Freedom From Distractibility Index, Arithmetic and Digit Span standard scores, and Digit Span forwards and backwards standard scores). Also in the clinical groups, the mean reproduction at the 400 ms interval of the estimation task was significantly associated with estimated Full Scale IQ (both Vocabulary and Block Design subtests), the WISC-III Processing Speed Index, and teacher reports of inattentive and hyperactive/impulsive behaviour. No significant associations were obtained with the achievement measures, and no significant associations were found between the time perception measures and the $2000 \mathrm{~ms}$ and $6000 \mathrm{~ms}$ intervals of the estimation task. The pattern of associations in Table 5 suggests that associations between these constructs differ between clinical and control groups. Consequently, regression analyses were performed to examine predictors of time perception performance, and these analyses permitted examination of the hypothesized association between time perception and working memory (Ivry, 1996).

Regression Analyses with the Clinical Groups on the Duration Discrimination and Estimation Tasks

Stepwise multiple regression analyses were performed with the duration discrimination and estimation tasks, as these constituted the time perception measures in this study. These analyses were done separately with the clinical (ADHD, ADHD+RD) and comparison control groups. The different pattern of associations between the clinical and control groups in Table 5 necessitated separate examinations of each group. The stepwise multiple regression procedure was selected in order to attempt to prioritize entry of the variables, as many of these cognitive measures are highly intercorrelated. Based on the correlation matrix presented in Table 5, predictors were selected based on their size of correlation (Tabachnick \& Fidell, 1989). The results of these regression analyses are presented in Table 6. 


\section{[Insert Table 6]}

Based on the correlations in Table 5, the working memory measures were examined as predictors of participants' performance on the duration discrimination task. Age was entered as the first predictor to control for age effects, followed by reading ability (as measured by the WRMT-R Word Identification subtest). Then, three working memory measures were entered, including the Digits Forward, Digits Backward, and Arithmetic Standard Scorers (all WISC-III test scores). The Digits Forward and Backward raw scores were considered as separate predictors for two reasons. First, their correlations with performance on the duration discrimination task differed, suggesting that Digits Forward performance may be more strongly tied to performance on this time perception measure. Second, theoretically, these two tasks involve different cognitive processes - namely, the Digits Forward involves holding and maintaining information, while the Digits Backward involves holding and manipulating information. Only the Digits Forward and Arithmetic Standard Scores entered into the equation as significant predictors of performance on the duration discrimination task. Other multiple regression analyses were conducted with full-scale IQ and the parent and teacher behaviour ratings, but none of these measures entered as significant predictors of performance. When this same regression analysis was conducted with the control group, none of these variables entered as significant predictors of performance on the duration discrimination task.

Performance on the duration estimation task at the 400 ms interval was most strongly correlated with estimated WISC-III Full-Scale IQ, the WISC-III Processing Speed Index score, and the teacher report of inattention and hyperactivity/impulsivity, as displayed in Table 5. A stepwise regression was performed, entering age, estimated Full-Scale IQ, the Processing Speed Index, and the teacher report of hyperactivity/impulsivity in this sequence. Estimated Full-Scale IQ and teacher report of hyperactivity and impulsivity were found to be significant predictors of performance on the estimation task at the $400 \mathrm{~ms}$ interval. In another analysis, teacher report of 
hyperactivity/impulsivity was entered before estimated Full-Scale IQ, and both continued to be significant predictors. Teacher report of inattention did not enter as a significant predictor. When these same regression analyses were conducted with the control group, none of these variables entered as significant predictors of performance on the estimation (400 ms interval) task.

\section{Discussion}

The purpose of the present investigation was to determine whether children and adolescents with ADHD exhibited deficits in time perception as predicted by current theory (Barkley, 1997). To do so, we used psychophysical tasks that require processing of temporal information with children (study 1) and with adolescents (study 2).

The present investigations yielded two major findings. With the stratification of ADHD on the basis of reading ability and the inclusion of a developmental contrast with children and adolescents, the present study provides evidence to suggest that children and adolescents with ADHD and ADHD+RD exhibit deficits in some aspects of time perception. Specifically, children with ADHD displayed less accurate performance on the duration discrimination task and displayed more intra-individual variability on the estimation task at $2000 \mathrm{~ms}$ and $6000 \mathrm{~ms}$ intervals, but no differences were obtained on the frequency discrimination control task. Children with ADHD+RD displayed less accurate performance on virtually all of the time perception measures, but not on the frequency discrimination control task. Adolescents with ADHD displayed significantly more intraindividual variability on the estimation task at the $2000 \mathrm{~ms}$ and $6000 \mathrm{~ms}$ intervals compared to comparison controls, but no differences with the ADHD group were obtained on the duration discrimination task as was reported in the sample of children (study 1). The ADHD+RD adolescent group displayed deficits across most of the time perception measures, but not on the frequency discrimination control task, as was found in study 1. 
Second, different variables were found to predict performance on the two time perception tasks examined in the sample of adolescents. Working memory measures were found to be significant predictors of performance on the duration discrimination task. Then, estimated Full-Scale IQ and teacher reported hyperactive/impulsive behaviours were found to be significant predictors of performance on the duration estimation task at the $400 \mathrm{~ms}$ interval.

\section{$\underline{\text { Time Perception and ADHD }}$}

There is evidence in the present investigation to suggest that time-related deficits are associated with ADHD. Specifically, children with ADHD (study 1) exhibited impairments in duration discrimination compared to the comparison group. This finding is in line with other investigations which have reported deficits in time perception with individuals with ADHD (Barkley, 1997; Barkley et al., 1997, 2001; Sonuga-Barke et al., 1998), and cerebellar deficits in ADHD (Castellanos, 2001; Castellanos et al., 1996, 2001). Also, both child and adolescent groups with ADHD displayed significantly more variability in performance than the comparison group on the estimation task. Importantly, this variability of performance on the estimation task has been found to be characteristic of patients with cerebellar or cortical lesions, who typically display timing deficits (Ivry, 1997). One possible explanation is that this variability is nonspecific to timing, and is a reflection of variability in attentional focus. Alternatively, the present findings raise the possibility that impairments in time perception and estimation of temporal task-parameters could account in part for the ubiquitous finding of extreme variability in response times in ADHD, across a variety of speeded response tasks (Leth-Steensen, Elbaz, \& Douglas, 2000; Tannock, 1998).

An even more consistent set of findings was obtained with the ADHD+RD group. It was hypothesized that this group would display deficits like the ADHD group, but perhaps even more impairment based on the additional RD comorbidity. Our hypothesis, however, was only partially supported, as the ADHD and the ADHD+RD groups did not display consistent performance trends 
on the time perception measures. In addition, the ADHD+RD group of adolescents displayed significantly lower scores on working memory measures (Digit Span Forwards and Backwards) compared to both the ADHD and comparison groups. This research therefore highlights the importance of considering comorbid-reading difficulties in these samples. However, since we did not include a reading disability group or another clinical comparison group, we cannot determine whether the deficit in time perception is specific to ADHD or common to other neurodevelopmental disorders, such as reading disabilities. The latter possibility has been investigated in-depth in the reading disability literature (Chiappe, Stringer, \& Siegel, \& Stanovich, 2002; Farmer \& Klein, 1995; Stringer, 1998; Stringer \& Stanovich, 2000; Tallal, 1980; Wolf, 2001), and deficits in timing are an important component of the double-deficit hypothesis of reading disability (Wolf, Bowers, \& Biddle, 2000; Wolf \& Bowers, 1999; Bowers \& Wolf, 1993). One study has reported selective impairments in duration discrimination at intervals longer than those used in the present study in children with reading disabilities, but no differences were reported on a frequency discrimination task (Nicholson et al., 1995). The inclusion of a reading-disabled group is essential in future investigations to determine shared and unique deficits in time perception. While time perception and timing-related deficits are not unique to either ADHD or RD, there are important theoretically based reasons to consider these two disorders together. Specifically, an important line of work has purported that ADHD and RD may share a similar genetic etiology (Willcutt et al., 2001), which highlights the importance of considering time perception deficits in both of these populations.

One critical difference between the two time perception measures used is the motor timing component in the estimation task. This difference has implications for providing an alternative explanation for the current findings. Inconsistent associations between time perception and motor timing performance has been described in the literature (Block, 1990), and empirical investigations of individuals with ADHD have provided evidence for impairments on both types of tasks (Rubia et 
al., 1999a; 1999b; Rubia et al., 2001; Smith, Warner Rogers, Newman, \& Rubia, 2002). In the current study, children with ADHD displayed impaired performance on the duration discrimination task, which is a more purely cognitive, not motor timing task, suggesting deficits in time perception, which is consistent with other work (Smith et al., in press).

Alternative explanations of these findings (i.e., other than a specific deficit in time perception) are also possible and must be considered. For example, the pattern of findings on the time perception measures may have been due to non-specific problems in processing auditory stimuli, or difficulties with the response requirements used in the tasks. The task design allows us to rule out the possibility of a general perceptual deficit or difficulty processing auditory information, since both tasks involved the presentation of brief auditory tones (either as boundary markers for the specific intervals, or as stimuli for the frequency discrimination task), but the impairments were specific to the duration discrimination task. Also, since both tasks used a forced choice response procedure and neither required a speeded response, we can rule out the possibility of a general difficulty with the type of decision-making that was required (i.e, first versus second stimulus) or slow response times.

Another possible explanation is that the psychophysical tasks used in the present study place demands on working memory and so the findings may reflect deficits in working memory that have been reported in ADHD (e.g., Barkley, 1997a; Mariani \& Barkley, 1997). This is because the tasks require a comparison between two successive stimuli, separated by a brief interval. The presentation of the first stimulus would have to be maintained across the interstimulus interval as well as during the presentation of the second stimulus, at least until a decision is reached. Such an operation is consistent with the functions of working memory (e.g., Baddeley, 1998; Goldman-Rakic, 1995). This function of working memory may then explain the seemingly counterintuitive finding that working memory measures were significantly associated with the duration discrimination task at the 
400 ms interval in the clinical adolescent sample. Specifically, the Digits Forward and Arithmetic Standard Scores were associated with performance on the duration discrimination task. Some investigators, such as Ivry (1996), have distinguished between short ( $<2$ seconds) and longer ( $>2$ seconds) durations; specifically, that shorter durations are linked to an internal timing mechanism, while longer durations may be related to functions of working memory. This distinction between short and long intervals has not held in the current empirical investigation, but there may be good reasons for the association. Working memory may inevitably play a role in tasks where judgements (frequency and duration discrimination task) or cognitive and motor coordination requirements must be integrated (duration estimation task). Given the task demands of making judgements or integrating cognitive and motor requirements would trail into longer intervals of time than the actual length of the stimuli, therefore, likely prompting functions of working memory. However, the working memory measures were not associated with performance on the estimation task, which is not inconsistent, as performance on discrimination and estimation tasks do not tend to co-vary together (Block, 1990). The results of study 2 with the adolescent sample, therefore, do implicate the role of working memory in performance on the most purely cognitive time perception measure - the duration discrimination task, but not on performance on the estimation task at the equally short interval.

Interestingly, performance on the estimation task was most strongly associated with estimated Full-Scale IQ and teacher reports of hyperactivity/impulsivity in the adolescent clinical sample. The estimation task was different from the discrimination task in many ways, but most obviously because of the motor reproduction component. The link between estimated Full-Scale IQ and estimation performance highlights the cognitive requirements in this task, and in this case, the link is with general cognitive ability. The relationship obtained between the estimation task and estimated Full-Scale IQ is not explanatory in terms of implicating specific cognitive mechanisms. 
However, the dissociation between the variables associated with each of the time perception measures continues to be an issue of interest - namely, that working memory measures were significantly associated with the frequency and duration discrimination tasks, but not the estimation task. Teacher reports of inattention and hyperactivity/impulsivity also predicted performance on the estimation task, and two possible interpretations may be considered. Either the teacher observations capture difficulties in the timing or synchronization of motoric behaviours, such as, calling out in class or jumping out of a seat, or the more general types of motoric difficulties described in ADHD samples. Interestingly, it is the teacher reports, not the parent reports, that predicted performance on the reproduction task. It may be the case that motoric difficulties are more obvious to teachers than to parents, as it is in classroom settings that ADHD children and adolescents are expected to perform in structured environments for extended periods of time. This finding is consistent with the literature that has demonstrated motor timing (Rubia et al., 1999a; 1999b; Rubia et al., 2001) and motor coordination deficits in ADHD samples (Beyer, 1999; Piek, Pitcher, \& Hay, 1999; Rubia et al., 1999a; 1999b; Sagvolden \& Sergeant, 1998; Steger, Imhof, Coutts, Gundelfinger, Steinhausen, \& Brandeis, 2001).

An additional consideration is the nature of the two samples studied in this investigation. Namely, study 1 was conducted with children and study 2 was conducted with adolescents, introducing developmental considerations in the interpretation of the results. In fact, some of the differences obtained in the child sample were not replicated in the adolescent sample. For example, children with ADHD and ADHD+RD displayed weaker duration discrimination performance in study 1, but only the adolescents with ADHD+RD displayed this effect in the adolescent sample. Also, differences on the estimation task in the child sample were no longer evident in the adolescent sample at intervals of $2000 \mathrm{~ms}$ and $6000 \mathrm{~ms}$. Given the positive direction of the results obtained, that is, that the adolescents displayed somewhat better performance on particular aspects of the time 
perception measures than children, these findings do suggest developmental influences on intact time perception abilities. With development, children become more capable and skilled at deploying resources and control in cognitive tasks (Zelazo \& Frye, 1998; Zelazo et al., 1997), which may impact performance on tasks such as those examined in the present investigation.

By contrast to the current beliefs that perceptual and sensory processes are intact in ADHD (Barkley, 1998; Douglas, 1999; Ross, Hommer, Breiger, Varley, \& Radant, 1994), the present findings suggest that some basic processes related to time perception are impaired in ADHD. Importantly, further consideration should be given to the relationship between time perception deficits and the highly comorbid disorders of ADHD and RD. These findings also suggest that aspects of time perception are related to working memory, and that deficits in these cognitive processes are separable from the motor control problems associated with ADHD. 


\section{References}

Baddeley, A. D., Gathercole, S., \& Papagano, C. (1998). The phonological loop as a languagelearning device. Psychological Review, 105, 158-173.

Barkley, R.A. (1997a). Behavioral inhibition, sustained attention, and executive functions: Constructing a unifying theory of ADHD. Psychological Bulletin, 121, 65-94.

Barkley, R. A. (1997b). Attention-deficit/hyperactivity disorder, self-regulation, and time: Toward a more comprehensive theory. Journal of Developmental \& Behavioral Pediatrics, 18, 271279.

Barkley, R. A. (1997c). ADHD and the nature of self control. New York: Guilford Press.

Barkley, R. A. (1998). Attention-deficit hyperactivity disorder: A handbook for diagnosis and treatment ( $2^{\text {nd }}$ Edition). New York: Guilford Press.

Barkley, R. A., Koplowitz S., Anderson T., \& McMurray, M.B. (1997). Sense of time in children with ADHD: Effects of duration, distraction and stimulant medication. Journal of the International Neuropsychological Society, 3, 359-369.

Barkley, R. A , Murphy, K. R., \& Bush, T. (2001). Time perception and reproduction in young adults with attention deficit hyperactivity disorder. Neuropsychology, 15(3), 351-360.

Barkley, R. A., Murphy K., \& Kwasnik, D. (1996). Psychological adjustment and adaptive impairments in young adults with ADHD. Journal of Attention Disorders, 1, 1-54.

Barratt, E. S., \& Patton, J. (1983). Impulsivity: cognitive, behavioral and psychological correlates. In M. Zuckerman (Ed), Sensation seeking; Beyond the optimal level of arousal (pp. 77-116). Hillsdale, NJ: Erlbaum.

Berquin, P. C., Giedd, J. N., Jacobsen, L. K., Hamburger, S. D., Krain, A. L., Rapoport, J. L., \& Castellanos, F. X. (1998). Cerebellum in attention-deficit hyperactivity disorder: A morphometric study. Neurology, 50, 1087-1093.

Beyer, R. (1999). Motor proficiency of boys with attention deficit hyperactivity disorder and boys with learning disabilities. Adapted Physical Activity Quarterly, 16(4), 403-414.

Block, R. A. (1990). Models of psychological time. In R. A. Block (Editor), Cognitive models of psychological time. Lawrence Erlbaum: Hillsdale, New Jersey.

Bowers, P. G., \& Wolf, M. (1993). Theoretical links among naming speed, precise timing mechanisms and orthographic skill in dyslexia. Reading \& Writing, 5(1), 69-85.

Capella, B., Gentile, J.R., \& Juliano, D. B. (1977). Time estimation by hyperactive and normal children. Perceptual \& Motor Skills, 44, 787-790. 
Casini, L., \& Ivry, R. B. (1999). Effects of divided attention on temporal processing in patients with lesions of the cerebellum or frontal lobe. Neuropsychology, 13, 10-21.

Castellanos, F. X. (2001). Neuroimaging studies of ADHD. In M. V. Solanto, A. F. T. Arnsten, \& F. X. Castellanos (Eds.), Stimulant drugs and ADHD: Basic and clinical neuroscience. Oxford University Press.

Castellanos, F. X., Giedd, J. N., Berquin, P. C., Walter, J. M., Sharp, W., Tran, T., Vaituzis, A. C., Blumenthal, J. D., Nelson, J., Bastain, T. M., Zijdenbos, A., Evans, A. C., \& Rapoport, J. L. (2001). Quantitative brain magnetic resonance imaging in girls with attentiondeficit/hyperactivity disorder. Archives of General Psychiatry, 58(3), 289-295.

Castellanos, F. X., Giedd, J. N., Marsh, W.L., Hamburger, S.D., et al.(1996). Quantitative brain magnetic resonance imaging in attention-deficit hyperactivity disorder. Archives of General Psychiatry, 53(7), 607-616.

Chiappe P., Stringer, R., Siegel, L. S., \& Stanovich, K. E. (2002). Why the timing deficit hypothesis does not explain reading disability in adults. Reading and Writing: An Interdisciplinary Journal, 15(1/2), 73-107.

Conners, C. K. (1997). Conners' Rating Scales-Revised: Technical Manual. New York: Multi-Health Systems Inc.

Douglas, V. I. (1999). Cognitive control processes in attention-deficit/hyperactivity disorder. In H. C. Quay \& A. E. Hogan (Eds.), Handbook of disruptive behavior disorders. New York: Kluwer Academic/Plenum Publishers.

Engle, R. W. (2002). Working memory capacity as executive attention. Current Directions in Psychological Science, 11(1), 19-23.

Engle, R. W., Tuholski, S. W., Laughlin, J.E., \& Conway, A. R. A. (1999). Working memory, shortterm memory and general fluid intelligence: A latent variable approach. Journal of Experimental Psychology: General, 128, 309-331.

Farmer, M. E., \& Klein, R. M. (1995). The evidence for a temporal processing deficit linked to dyslexia: A review. Psychonomic Bulletin \& Review, 2(4), 460-493.

Fawcett, A. J., Nicolson, R. I. (2001). Speed and temporal processing in dyslexia. In M. Wolf (Ed.), Dyslexia, fluency and the brain. Timonium, Maryland: York Press, Inc.

Fletcher, J. M., Francis, D. J., Shaywitz, S. E., Lyon, G. R., Foorman, B. R., Stuebing, K. K., \& Shaywitz, B. A. (1998). Intelligent testing and the discrepancy model for children with learning disabilities. Learning Disabilities Research \& Practice, 13, 186-202.

Francis, D. J., Fletcher, J. M., Shaywitz, B. A., Shaywitz, S. E., \& Rourke, B. P. (1996). : Defining learning and language disabilities: Conceptual and psychometric issues with the use of IQ tests. Language, Speech, and Hearing Services in Schools, 27, 132-143. 
Frankenberger, W., \& Fronzaglio, K. (1991). A review of states' criteria for identifying children with learning disabilities. Journal of Learning Disabilities, 24, 495-500.

Gerbing, D. W., Ahadi, S. A., \& Patton, J. H. (1987). Towards a conceptualisation of impulsivity: Components across the behavioural and self-report domain. Multivariate Behavioural Research, 22, 357-379.

Gibbon, J., Malapani, C.L., Dale, C.L., \& Gallistel, C. R. (1997). Toward a neurobiology of temporal cognition: advances and challenges. Current Opinion in Neurobiology, 7, 170-184.

Goldman-Rakic, P. S. (1995). Architecture of the prefrontal cortex and the central executive. In Grafman, J., Holyoak, K. J., Jamies, K. et al. (Eds.), Structure and functions of the human prefrontal cortex. Annals of the New York Academy of Sciences, Vol. 769. (pp. 71-83). New York: New York Academy of Sciences.

Harrington, D. L., Haaland, K. Y., \& Hermanowicz, N. (1998a). Temporal processing in the basal ganglia. Neuropsychology, 12, 1-10.

Harrington, D. L., Haaland, K. Y., \& Knight, R. T. (1998b). Cortical networks underlying mechanisms of time perception. Journal of Neuroscience, 18, 1085-1095.

Hazeltine, E., Helmut, L. L., \& Ivry, R. B. (1998). Neural mechanisms of timing. Trends in Cognitive Science, 1, 163-169.

Hetherington, R., Dennis, M., \& Spiegler, B. (2000). Perception and estimation of time in long-term survivors of childhood posterior fossa tumors. Journal of the International Neuropsychological Society, 6(6): 682-692.

Ivry, R. B. (1996). The representation of temporal information in perception and motor control. Current Opinion in Neurobiology, 6, 851-857.

Ivry, R. B. (1997). Cerebellar timing systems. International Review of Neurobiology, 41, 555-573.

Ivry, R. B., Hazeltine, R. E. (1995). Perception and production of temporal intervals across a range of durations: Evidence for a common timing mechanism. Journal of Experimental Psychol: Human Perception and Performance, 21, 3-18.

Ivry, R.B., \& Keele, S. W. (1989). Timing functions of the cerebellum. Journal of Cognitive Neuroscience, 1, 136-152.

Jueptner, M., Rijntjes, M., Weiller, C., Faiss, J. H., Timmann, D., Mueller, S. P., \& Diener, H. C. (1995). Localization of a cerebellar timing process using PET. Neurology, 45, 1540-1545.

Jueptner, M., Flerlch, L., Weiller, C., Mueller, S., \& Diener, H. C. (1996). The human cerebellum and temporal information processing - results from a PET experiment. Neuroreport, 7, 27612765. 
Kaplan, E., Fein, D., Kramer, J., Delis, D., Morris, R. (1999). WISC-III PI Manual. USA: The Psychological Corporation.

Karetekin, C., \& Asarnow, R. F. (1998). Working memory deficits in childhood-onset schizophrenia and attention-deficit/hyperactivity disorder. Psychiatry Research, 80, 165-176.

Kaufman, J., Birmaher, B., Brent, D., Rao, U., Flynn, C., Moreci, P., Williamson, D., \& Ryan, N. (1997). Schedule for affective disorders and schizophrenia for school-aged children present and lifetime version (K-SADS-PL): Initial reliability and validity data. Journal of the American Academy of Child and Adolescent Psychiatry, 36, 980-988.

Kirk, R. E. (1982). Experimental design: Procedures for the behavioral sciences (2 ${ }^{\text {nd }}$ Edition). Pacific Grove, California: Brooks/Cole Publishing Company.

Leth-Steensen, C., Elbaz, Z. K., \& Douglas, V. I. (2000). Mean response times, variability and skew in responding of ADHD children: A response time distributional approach. Acta Psychologica, 104(2), 167-190.

Mangels, J. A., Ivry R. B., \& Shimizu, N. (1998). Dissociable contributions of the prefrontal and neocerebellar cortex to time perception. Cognitive Brain Research, 7, 15-39.

Mariani, M. A., \& Barkley, R. A. (1997). Neuropsychological and academic functioning in preschool boys with Attention Deficit Hyperactivity Disorder. Developmental Neuropsychology, 13, 111-129.

Meck, W. H. (1996). Neuropharmacology of timing and time perception. Cognitive Brain Research, 3, 227-242.

Miyake A.,\& Shah, P. (1999). Models of working memory: Mechanisms of active maintenance and executive control. Cambridge: Cambridge University Press.

Mostofsky, S. H., Reiss, A. L., Lockhart, P., \& Denckla, M. B. (1998). Evaluation of cerebellar size in attention-deficit hyperactivity disorder. Journal of Child Neurology. 13(9), 434-439.

Mostofsky, S. H., Kunze, J. C., Cutting, L. E., Lederman, H. M., \& Denckla, M. B. (2000). Judgment of duration in individuals with ataxia-telangiectasia. Developmental Neuropsychology, 17(1), 63-74.

Nichelli, P., Always, D., \& Grafman, J. (1996a). Perceptual timing in cerebellar degeneration. Neuropsychologica, 34, 863-871.

Nichelli, P. (1996b). Time perception measurements in neuropsychology. In M. A. Pastor, \& J. Artieda (Eds), Time, Internal Clocks, and Movement Vol 115 (pp. 187-204). Amsterdam: Elsevier.

Nicolson, R. I., Fawcett, A. J., \& Dean, P. (2001). Developmental dyslexia: The cerebellar deficit hypothesis. Trends in Neurosciences, 24(9), 508-511. 
Piek, J. P., Pitcher, T. M., \& Hay, D. A. (1999). Motor coordination and kinaesthesis in boys with attention deficit-hyperactivity disorder. Developmental Medicine and Child Neurology, 41, 159-165.

Ross, R. G., Hommer, D., Breiger, D., Varley, C., \& Radant, A. (1994). Eye movement task related to frontal lobe functioning in children with attention deficit disorder. Journal of the American Academy of Child and Adolescent Psychiatry, 33, 869-874.

Rubia, K., Overmeyer, S., Taylor, E., Brammer, M., Williams, S. C. R., Simmons, A., Bullmore, E. T. (1999a). Hypofrontality in Attention Deficit Hyperactivity Disorder during higher-order motor control: A study with functional MRI. American Journal of Psychiatry, 156 (6), 891896.

Rubia, K., Taylor, A., Taylor, E., \& Sergeant, J. A. (1999b). Synchronization, anticipation, and consistency in motor timing of children with dimensionally defined Attention Deficit Hyperactivity Disorder. Perceptual and Motor Skills, 89, 1237-1258.

Sagvolden, T., Sergeant, J. A. (1998). Attention deficit/hyperactivity disorder: From brain dysfunctions to behaviour. Behavioural Brain Research, 94(1), 1-10.

Schachar, R., Tannock, R., Marriott, M., \& Logan, G. (1995). Deficient inhibitory control in attention deficit hyperactivity disorder. Journal of Abnormal Child Psychology, 23(4), 411437.

Sergeant, J. A., \& Scholten, C. A. (1985). On resource strategy limitations in hyperactivity: cognitive impulsivity reconsidered. Journal of Child Psychology and Psychiatry and Allied Disciplines, 26, 97-109.

Smith, A., Taylor, E., Warner Rogers, J., Newman, S., \& Rubia, K. (2002). Evidence for a pure time perception deficit in children with ADHD. Journal of Child Psychology and Psychiatry, 43(4), 529-542.

Sonuga-Barke, E. J. S., Saxton, T., Hall, M. (1998). The role of interval underestimation in hyperactive children's failure to suppress responses over time. Behavioral Brain Research, $94,45-50$.

Stanford, M. S., Barratt, E. S. (1996). Verbal skills, finger tapping, and cognitive tempo define a second-order factor of temporal information processing. Brain \& Cognition, 31, 35-45.

Stanovich, K. E., \& Siegel, L. S. (1994). Phenotypic performance profiles of children with reading disabilities: A regression-based test of the phonological-core variable difference model. Journal of Educational Psychology, 86, 24-53.

Steger, J., Imhof, K., Coutts, E., Gundelfinger, R., Steinhausen, H.-Ch., Brandeis, D. (2001). Attentional and neuromotor deficits in ADHD. Developmental Medicine and Child Neurology, 43, 172-179. 
Stringer, R. W. (1998). Adult reading disability and temporal processing deficits. Dissertation Abstracts International, 59(6A).

Stringer, R. W., Stanovich, K. E. (2000). The connection between reaction time and variation in reading ability: Unravelling covariance relationships with cognitive ability and phonological sensitivity. Scientific Studies of Reading, 4(1): 41-53.

Tabachnick, B. G., Fidell, L. S. (1989). Using multivariate statistics $2^{\text {nd }}$ Edition. New York: Harper Collins.

Tallal, P. (1980). Auditory temporal perception, phonics, and reading disabilities in children. Brain and Language, 9, 182-198.

Tannock, R. (1998). Attention deficit hyperactivity disorder: Advances in cognitive, neurobiological, and genetic research. Journal of Child Psychology and Psychiatry and Allied Disciplines, 39(1), 65-99.

Tannock, R., Hum, M., Masellis, M., Humphries, T., \& Schachar, R. (1999). Children's academic performance, attention, behavior, and learning evaluation: Teacher telephone interview (Capable-TTI) Guidelines. Toronto: Hospital for Sick Children Brain and Behavior Research Program (rosemary.tannock@sickkids.ca).

Tiholov, T. T., Zawallich, A., Janzen, H. L. (1996). Diagnosis based on the WISC-III processing speed factor. Canadian Journal of School Psychology, 12(1), 23-34.

Wechsler, D. (1991). Manual for the WISC III. New York: Psychological Corporation.

Wetherill, G. B., Levitt, H. (1965). Sequential estimation of points on a psychological function. British Journal of Math and Statistical Psychology, 18, 1-10.

Wilkinson G. S. (1993). WRAT3 Administration Manual. Delaware: Wide Range.

Willcutt, E. G., Pennington, B. F., Boada, R., Ogline, J. S., Tunick, R. A., Chhabildas, N. A., \& Olson, R. K. (2001). A comparison of the cognitive deficits in reading disability and attention-deficit/hyperactivity disorder. Journal of Abnormal Psychology, 110(1), 157-172.

Williams, B. R., Ponesse, J. S., Schachar, R. J., Logan, G. D., \& Tannock, R. (1999). Development of inhibitory control across the life span. Developmental Psychology, 35(1): 205-213.

Wolf, M. (2001). Dyslexia, fluency, and the brain. (Edited volume). Timonium, Maryland: York Press, Inc.

Wolf, M., \& Bowers, P. G (1999). The double-deficit hypothesis for the developmental dyslexias. Journal of Educational Psychology, 91(3): 415-438. 
Wolf, M., Bowers, P. G., \& Biddle, K. (2000). Naming-speed processes, timing, and reading: A conceptual overview. Journal of Learning Disabilities, 33(4), 387-407.

Woodcock, R. W. (1987). Woodcock Reading Mastery Tests - Revised. American Guidance Service Inc.

Zahn, T. P., Kruesi, M. J. P., \& Rapoport, J. L. (1991). Reaction time indices of attention deficits in boys with disruptive behavior disorders. Journal of Abnormal Child Psychology, 19, 233252.

Zakay, D. (1990). The evasive art of subjective time measurement: Some methodological dilemmas. In R.A. Block (Ed.), Cognitive models of psychological time (pp. 85-101). Hillsdale, NJ: Lawrence Erlbaum Associates.

Zelazo, P. D., Carter, A., Reznick, J. S., \& Frye, D. (1997). Early development of executive function: A problem-solving framework. Review of General Psychology, 1(2), 198-226.

Zelazo, P. D., \& Frye, D. (1998). Cognitive complexity and control: II. The development of executive function in childhood. Current Directions in Psychological Science, 7(4), 121-126. 
Table 1. Diagnostic Characteristics of the ADHD and ADHD+RD Groups ${ }^{a}$ in the Child Sample (Study 1)

\begin{tabular}{|c|c|c|c|c|c|c|}
\hline & ADHD & $\mathrm{n}$ & $\mathrm{ADHD}+\mathrm{RD}$ & $\mathrm{n}$ & df & $\mathrm{F}$ \\
\hline Age & $8.9(1.3)$ & 31 & $8.9(1.3)$ & 19 & 2,97 & $1.35^{\mathrm{b}}$ \\
\hline \multicolumn{7}{|l|}{ WISC-III Scale Scores } \\
\hline VIQ & $110.6(15.3)$ & 30 & $101.2(11.8)$ & 19 & 1,47 & $5.18^{*}$ \\
\hline PIQ & $102.7(16.2)$ & 30 & $103.5(12.5)$ & 19 & 1,47 & 0.03 \\
\hline \multicolumn{7}{|l|}{ WISC-III Index Scores } \\
\hline Verbal Comprehension & $111.1(16.3)$ & 29 & $102.0(13.9)$ & 19 & 1,46 & 4.03 \\
\hline Perceptual Organization & $102.4(15.7)$ & 29 & $104.1(14.8)$ & 19 & 1,46 & 0.13 \\
\hline Freedom from Distractibility & $99.3(12.1)$ & 29 & $95.3(8.0)$ & 19 & 1,46 & 1.60 \\
\hline Processing Speed & $107.2(17.1)$ & 28 & $100.11(12.4)$ & 18 & 1,44 & 2.31 \\
\hline \multicolumn{7}{|l|}{ WISC-III Subtest Standard Scores } \\
\hline Vocabulary & $12.0(3.6)$ & 29 & $10.3(3.0)$ & 19 & 1,47 & 2.93 \\
\hline Block Design & $10.7(3.9)$ & 29 & $11.5(3.7)$ & 19 & 1,47 & 0.49 \\
\hline Digit Span & $9.0(3.1)$ & 29 & $8.9(2.5)$ & 19 & 1,47 & 0.03 \\
\hline Arithmetic & $10.7(2.5)$ & 29 & $9.3(1.6)$ & 19 & 1,47 & $5.14 *$ \\
\hline \multicolumn{7}{|l|}{ Reading Measures } \\
\hline WRAT-3 Reading & $104.5(10.3)$ & 30 & $86.0(7.5)$ & 19 & 1,47 & $45.99 * * *$ \\
\hline WRMT-R Word Identification & $105.1(11.5)$ & 30 & $80.5(5.4)$ & 19 & 1,47 & $75.79 * * *$ \\
\hline WRMT-R Word Attack & $99.0(8.3)$ & 30 & $81.3(5.8)$ & 19 & 1,47 & $66.19 * * *$ \\
\hline \multicolumn{7}{|l|}{ Arithmetic measures } \\
\hline WRAT-3 Arithmetic & $94.1(10.2)$ & 30 & $88.7(9.9)$ & 19 & 1,47 & 3.40 \\
\hline \multicolumn{7}{|c|}{ Diagnostic Characteristics (\# symptoms) } \\
\hline PICS Inattention & $5.3(2.0)$ & 31 & $5.6(2.1)$ & 19 & 1,48 & 0.33 \\
\hline PICS Hyperactivity/Impulsivity & $5.7(1.8)$ & 31 & $6.0(1.9)$ & 19 & 1,48 & 0.29 \\
\hline TTI Inattention & $5.5(2.4)$ & 28 & $5.7(1.8)$ & 18 & 1,44 & 0.08 \\
\hline TTI Hyperactivity/Impulsivity & $4.0(2.5)$ & 28 & $3.8(2.5)$ & 18 & 1,44 & 0.05 \\
\hline \multicolumn{7}{|l|}{ Comorbidity (\% of sample) } \\
\hline Oppositional Defiant Disorder & $39 \%$ & 12 & $42 \%$ & 8 & & \\
\hline Conduct Disorder & $16 \%$ & 5 & $21 \%$ & 4 & & \\
\hline Separation Anxiety & $10 \%$ & 3 & $11 \%$ & 2 & & \\
\hline \multicolumn{7}{|c|}{ ADHD Subtypes (\% of clinical sample) } \\
\hline Inattentive Subtype & $23 \%$ & 7 & $21 \%$ & 4 & & \\
\hline
\end{tabular}

\footnotetext{
${ }^{\mathrm{b}}$ Comparison with ADHD, ADHD+RD, and normal controls
} 


\begin{tabular}{lllll}
\hline Hyperactive/Impulsive Subtype & $0 \%$ & 0 & $0 \%$ & 0 \\
Combined Subtype & $77 \%$ & 24 & $79 \%$ & 15 \\
\hline
\end{tabular}

${ }^{\mathrm{a}}$ No psychometric data were available for the normal controls. $* * * \mathrm{p}<.001, * \mathrm{p}<.05$ 
Table 2. Means (Standard Deviation) for Frequency and Duration Discrimination

Tasks and Three Interval Reproduction Tasks for ADHD and Control Groups

\begin{tabular}{|c|c|c|c|c|}
\hline & $\begin{array}{c}\text { ADHD } \\
\text { (1) }\end{array}$ & $\begin{array}{c}\text { ADHD+RD } \\
\text { (2) }\end{array}$ & $\begin{array}{c}\text { Control Group } \\
\text { (3) }\end{array}$ & Posthoc Analyses \\
\hline \multicolumn{5}{|c|}{ Frequency and Duration Discrimination $^{\mathrm{a}}$} \\
\hline Frequency $(3000 \mathrm{~Hz})$ & $3022.8(8.8)$ & 3018.0 ( 7.7) & $3019.9(9.8)$ & n.s. \\
\hline Duration $(400 \mathrm{~ms})^{\mathrm{b}}$ & $563.1(67.1)$ & $558.6(67.7)$ & $514.6(38.7)$ & $1,2>3$ \\
\hline \multicolumn{5}{|c|}{ Duration Estimation by Method of Reproduction $^{c}$} \\
\hline $400 \mathrm{~ms}$ : Mean & $579.0(203.0)$ & $628.3(246.2)$ & $501.2(129.6)$ & $2>1,3$ \\
\hline : SD & $423.4(409.4)$ & $565.1(551.0)$ & 230.6 (301.3) & $2>1,3$ \\
\hline 2000 ms: Mean & 1957.5 ( 519.8) & $1728.6(361.9)$ & $1983.2(292.2)$ & n.s. \\
\hline : SD & 748.6 ( 346.5$)$ & 877.1 (527.6) & $523.9(224.8)$ & $1,2>3$ \\
\hline 6000 ms: Mean & 4122.7 (1402.5) & 3390.4 (1317.5) & $4524.3(1055.2)$ & $1,3>2$ \\
\hline : SD & $1571.3(584.9)$ & $1811.8(710.8)$ & 1102.9 (392.8) & $1,2>3$ \\
\hline
\end{tabular}

\footnotetext{
${ }^{a}$ Frequency Discrimination: $F(2,97)=1.80$, ns; Duration Discrimination: $F(2,97)=8.82, p<.001$.

${ }^{\mathrm{b}}$ Data missing for $1 \mathrm{ADHD}$ and 2 control subjects due to equipment problems; corresponding change in df for the F-ratio (2,94).

${ }^{\mathrm{c}}$ Estimation Task Reproductions: Main effect for group: $F(2,97)=4.67, p<.05$; Main effect for interval: $F(2,194)=580.94, p<$ .0001 ; Group X interval interaction: $F(4,194)=6.60, p<.0001$. Estimation Task Variability: Main effect for group: $F(2,97)=17.66, p$ $<.0001$ ]; Main effect for interval: $F(2,194)=223.49, p<.0001$; Group X interval interaction: $F(4,194)=3.30, p<.05$.
} 
Table 3. Diagnostic Characteristics of the ADHD, ADHD+RD, and Comparison Control Groups in the Adolescent Sample (Study 2)

\begin{tabular}{|c|c|c|c|c|c|c|c|c|c|}
\hline & $\begin{array}{c}\text { ADHD } \\
(1)\end{array}$ & $\mathrm{n}$ & $\begin{array}{c}\mathrm{ADHD}+\mathrm{RD} \\
(2)\end{array}$ & $\mathrm{n}$ & $\begin{array}{c}\text { Controls } \\
(3)\end{array}$ & $\mathrm{n}$ & df & $\mathrm{F}$ & Posthoc \\
\hline Age & $15.2(1.4)$ & 35 & $14.9(1.4)$ & 24 & $15.0(1.2)$ & 39 & 2,95 & 0.45 & n.s. \\
\hline \multicolumn{10}{|l|}{ WISC-III Standard Scores } \\
\hline Estimated FSIQ & $102.2(8.7)$ & 35 & $101.1(12.1)$ & 24 & $110.1(13.0)$ & 39 & 2,95 & $6.24^{* *}$ & $3>1,2$ \\
\hline Vocabulary Standard Score & $10.3(2.1)$ & 35 & $8.5(2.2)$ & 24 & $11.6(2.7)$ & 39 & 2, 95 & $12.18 * * *$ & $1,3>2$ \\
\hline Block Design Standard Score & 10.5 (1.9) & 35 & $11.5(3.9)$ & 24 & $11.8(3.4)$ & 39 & 2,95 & 1.75 & n.s. \\
\hline \multicolumn{10}{|l|}{ WISC-III Index Scores } \\
\hline Freedom from Distractibility & $102.3(14.2)$ & 34 & $84.1(13.7)$ & 23 & $106.9(14.2)$ & 37 & 2,91 & $19.54 * * *$ & $1,3>2$ \\
\hline Processing Speed & 99.1 (17.3) & 33 & $102.6(16.2)$ & 23 & $118.4(13.6)$ & 37 & 2,90 & $15.22 * * *$ & $3>1,2$ \\
\hline \multicolumn{10}{|l|}{ Achievement Measures Standard Scores } \\
\hline WRAT-3 Reading & $105.7(7.6)$ & 35 & $87.2(13.3)$ & 24 & $110.9(7.4)$ & 39 & 2,95 & $50.68 * * *$ & $3>1>2$ \\
\hline WRAT- 3 Spelling & $103.9(7.9)$ & 35 & $81.4(10.4)$ & 24 & $111.6(8.6)$ & 39 & 2,95 & $88.69 * * *$ & $3>1>2$ \\
\hline WRAT-3 Arithmetic & $96.8(12.9)$ & 35 & $87.3(16.9)$ & 24 & $111.3(10.6)$ & 39 & 2, 95 & $26.72 * * *$ & $3>1>2$ \\
\hline WRMT-R Word Identification & $103.9(7.9)$ & 35 & $86.0(13.4)$ & 24 & $105.9(5.7)$ & 39 & 2,95 & $42.36 * * *$ & $1,3>2$ \\
\hline WRMT - R Word Attack & $102.0(5.5)$ & 35 & $87.1(8.2)$ & 24 & $103.3(7.1)$ & 39 & 2,95 & $46.93 * * *$ & $1,3>2$ \\
\hline \multicolumn{10}{|l|}{ Diagnostic Characteristics (\# symptoms) } \\
\hline KSADS Inattention - Parent & $7.8(1.4)$ & 35 & $7.3(1.4)$ & 24 & $0.5(1.8)$ & 39 & 2,95 & $241.44 * * *$ & $1,2>3$ \\
\hline KSADS Hyperactivity/Impulsivity - Parent & $4.8(2.9)$ & 35 & $5.5(2.4)$ & 24 & $0.6(1.4)$ & 39 & 2,95 & $47.40 * * *$ & $1,2>3$ \\
\hline Conners Inattention - Parent & $74.3(12.2)$ & 35 & $70.5(19.0)$ & 24 & $47.1(5.6)$ & 39 & 2,95 & $51.25 * * *$ & $1,2>3$ \\
\hline Conners Hyperactivity/Impulsivity - Parent & $68.8(14.2)$ & 35 & 70.0 (19.9) & 24 & $49.1(5.3)$ & 39 & 2,95 & $26.61 * * *$ & $1,2>3$ \\
\hline Conners Inattention - Teacher & $66.7(17.6)$ & 35 & $68.0(18.0)$ & 24 & $42.3(13.0)$ & 39 & 2,95 & $28.47 * * *$ & $1,2>3$ \\
\hline Conners Hyperactivity/Impulsivity - & $65.7(20.0)$ & 35 & 63.5 (20.8) & 24 & $42.9(13.2)$ & 39 & 2,95 & $17.80^{* * *}$ & $1,2>3$ \\
\hline
\end{tabular}




\begin{tabular}{|c|c|c|c|c|c|c|}
\hline \multicolumn{7}{|l|}{ Teacher } \\
\hline \multicolumn{7}{|l|}{ Comorbid Disorders (\% of sample) } \\
\hline Oppositional Defiant Disorder & $37 \%$ & 13 & $25 \%$ & 6 & $0 \%$ & 0 \\
\hline Generalized Anxiety Disorder & $23 \%$ & 8 & $21 \%$ & 5 & $3 \%$ & 1 \\
\hline \multicolumn{7}{|l|}{ ADHD Subtypes (\% of clinical sample) } \\
\hline Hyperactive/Impulsive Subtype & $0 \%$ & 0 & $0 \%$ & 0 & N/A & \\
\hline Combined Subtype & $17 \%$ & 6 & $64 \%$ & 7 & N/A & \\
\hline
\end{tabular}

${ }^{* * *} \mathrm{p}<.001,{ }^{* *} \mathrm{p}<.01,{ }^{*} \mathrm{p}<.05$ 
Table 4. Means (Standard Deviation) for Frequency, Duration Discrimination and

Estimation Tasks for ADHD Adolescent and Comparison Groups (Study 2)

\begin{tabular}{|c|c|c|c|c|}
\hline & $\begin{array}{c}\text { ADHD } \\
\text { (1) }\end{array}$ & $\begin{array}{c}\text { ADHD+RD } \\
\text { (2) }\end{array}$ & $\begin{array}{c}\text { Control Group } \\
\text { (3) }\end{array}$ & Posthoc \\
\hline \multicolumn{5}{|c|}{ Frequency and Duration Discrimination ${ }^{\mathrm{a}}$} \\
\hline Frequency $(3000 \mathrm{~Hz})$ & $3019.5(8.2)$ & 3017.85 (8.08) & 3016.84 (5.67) & n.s. \\
\hline Duration (400 ms) & $492.7(36.4)$ & $510.4(47.6)$ & $485.4(29.2)$ & $2>1,3$ \\
\hline \multicolumn{5}{|c|}{ Duration Estimation by Method of Reproduction $^{\text {b }}$} \\
\hline $400 \mathrm{~ms}$ : Mean & $519.9(177.5)$ & $577.3(198.4)$ & $463.0(72.2)$ & $2>1,3$ \\
\hline : SD & $259.2(410.0)$ & $365.1(465.1)$ & $101.2(102.4)$ & $2>1,3$ \\
\hline 2000 ms: Mean & 2166.9 (319.9 & 2219.0 (397.6) & 2040.8 (314.7) & n.s. \\
\hline : SD & $616.2(409.8$ & 695.8(343.9 & $340.4(173.6)$ & $1,2>3$ \\
\hline 6000 ms: Mean & $5347.9(643.2)$ & $5249.1(890.1)$ & $5590.0(571.5)$ & n.s. \\
\hline : SD & 1153.5 (523.3) & $1281.7(657.2)$ & $626.4(263.5)$ & $1,2>3$ \\
\hline
\end{tabular}

\footnotetext{
${ }^{a}$ Frequency Discrimination: $F(2,94)=1.26$; n.s.; Duration Discrimination: $F(2,94)=3.44, p<.05$.

${ }^{\mathrm{b}}$ Estimation Task Reproductions: Main effect for group: $F(2,94)=0.02$, n.s.; Main effect for interval: $F(2,188)=3584.74, p<.0001$; Group X interval interaction: $[F(4,188)=4.41, p<.01]$. Estimation Task Variability: Main effect for group: $F(2,94)=23.83, p<$ .0001 ; Main effect for interval: $F(2,188)=123.22, p<.0001$; Group X interval interaction: $F(4,188)=3.92, p<.01$.
} 
Table 5. Zero-Order Correlations between Measures of Time Perception and Intellectual and Academic Abilities in Clinical (ADHD, ADHD+RD) and Comparison Adolescents (Study 2)

\begin{tabular}{|c|c|c|c|c|c|c|}
\hline & \multicolumn{2}{|c|}{$\begin{array}{l}\text { FREQ Threshold } \\
(3000 \mathrm{HZ})\end{array}$} & \multicolumn{2}{|c|}{$\begin{array}{l}\text { DUR Threshold } \\
\text { (400ms) }\end{array}$} & \multicolumn{2}{|c|}{$\begin{array}{l}\text { Estimation Task at } \\
400 \text { ms Interval }\end{array}$} \\
\hline & Clinical & Control & Clinical & Control & Clinical & Control \\
\hline \multicolumn{7}{|l|}{ WISC-III Scores } \\
\hline Estimated FSIQ & .17 & -.23 & -.14 & .09 & $-.35 * *$ & .15 \\
\hline Freedom From Distractibility Index & .12 & $-.45 * *$ & $-.50 * * *$ & .09 & -.07 & -.19 \\
\hline Processing Speed Index & .03 & -.26 & -.26 & .00 & $-.28 *$ & -.16 \\
\hline Arithmetic Standard Score & .11 & $-.34 *$ & $-.42 * * *$ & .04 & -.05 & -.26 \\
\hline Digit Span Standard Score & .10 & $-.41 * *$ & $-.46 * * *$ & .12 & -.07 & -.05 \\
\hline Digit Span - Forwards Standard Score & .17 & $-.40 * *$ & $-.43 * * *$ & -.05 & -.12 & -.10 \\
\hline Digit Span - Backwards Standard Score & -.01 & $-.42 * *$ & $-.33 *$ & .05 & .04 & -.10 \\
\hline \multicolumn{7}{|l|}{ Behaviour/Diagnostic Measures } \\
\hline $\begin{array}{c}\text { Parent K-SADS-Inattention } \\
\text { PAD }\end{array}$ & -.01 & $.32 *$ & -.05 & .07 & -.04 & -.13 \\
\hline Parent K-SADS- Hyperactive/Impulsive & .05 & $.36^{*}$ & -.02 & .20 & -.20 & -.08 \\
\hline Parent Conners-Inattention & .08 & -.05 & .06 & .18 & -.06 & -.08 \\
\hline Parent Conners-Hyperactive & .15 & -.05 & .03 & .12 & .03 & -.16 \\
\hline Teacher Conners-Inattention & -.12 & .20 & .12 & -.09 & $.27 *$ & .09 \\
\hline Teacher Conners-Hyperactive/Impulsive & -.15 & .23 & .12 & -.20 & $.34 * *$ & .07 \\
\hline
\end{tabular}

$* * * \mathrm{p}<.001, * * \mathrm{p}<.01,{ }^{*} \mathrm{p}<.05$ 
Table 6. Stepwise Regression Analyses using Clinical (ADHD, ADHD+RD) Adolescent Sample (Study 2)

\begin{tabular}{|c|c|c|c|}
\hline & $\begin{array}{c}\text { Standardized Beta } \\
\text { Weight }\end{array}$ & t-value & Partial r \\
\hline \multicolumn{4}{|l|}{ Criterion Variable: DUR Threshold } \\
\hline Step 1: Age & -.03 & -.24 & -.03 \\
\hline Step 2: WRMT-R Word Identification SS & -.03 & -.19 & -.03 \\
\hline Step 3: Digits Forward WISC-III Standard Score & -.43 & $-3.47 * * *$ & -.43 \\
\hline Step 4: Digits Backward WISC-III Standard Score & -.16 & -1.08 & -.15 \\
\hline Step 5: Arithmetic WISC-III Standard Score & -.27 & $-2.01 *$ & -.27 \\
\hline \multicolumn{4}{|l|}{$\begin{array}{l}\text { Overall Regression } \mathrm{F}=12.07^{* * *} \\
\text { Multiple } \mathrm{R}=.43 \\
\text { Multiple R-squared }=.19\end{array}$} \\
\hline \multicolumn{4}{|l|}{ Criterion Variable: 400 ms Reproduction Task } \\
\hline Step 1: Age & .14 & 1.10 & .15 \\
\hline Step 2: WISC-III Estimated FSIQ ${ }^{1}$ & -.27 & $-2.12 *$ & -.28 \\
\hline Step 3: WISC-III Processing Speed Index Score & -.18 & -1.35 & -.19 \\
\hline $\begin{array}{l}\text { Step 4: Conners’ Teacher Report - } \\
\text { Hyperactive/Impulsive Scale }\end{array}$ & .27 & $2.09 *$ & .28 \\
\hline $\begin{array}{l}\text { Overall Regression } \mathrm{F}=5.98^{* *} \\
\text { Multiple } \mathrm{R}=.43 \\
\text { Multiple R-squared }=.19\end{array}$ & & & \\
\hline
\end{tabular}

\footnotetext{
${ }^{1}$ This estimate is a composite based on Vocabulary and Block Design subtest scores.
} 